\title{
A POLfTICA DE REPRODUÇÃO BIOLÓGICA HUMANA NO BRASIL
}

Maria Amélia de Campos Oliveira*

()!_IVEIRA, M.A. de C. A politica de reprodução biológica humana no Brasil. Rev. Esc. Enf. USP, v. 26, n. 2, p. 155-60, Ago. 1992.

A autora recupera alguns dos determinantes históricos da politica de reprodução humana no Brasil, situando-a no conjunto das politicas sociais. Argumenta que a reprodução biológica não é a única a condicionar o perfil reprodutivo das classes, sendo necessário considerar ainda a reprodução da força de trabalho, dada pelas formas de trabalho e consumo em cada classe social.

UNITERMOS: Reprodução biológica humana. Planejamento familiar. Controle da natalidade.

O campo para o qual convergem as questões ligadas à população e ao desenvolvimento e que se constitui domínio formal da demografia, apresenta-se como um exemplo de interdisciplinaridade: nele se desen. volvem as práticas investigativas não apenas de demógrafos, mas de historiadores, antropólogos, sociólogos e, mais recentemente, de pesquisadores da área da saúde. Voltados para esse campo também estão os interesses de diferentes segmentos da sociedade, tais como grupos políticos e religiosos, para os quais a reprodução humana é objeto de interesse e controvérsia ${ }^{11}$.

Para entender o porquê da polarização do tema entre controlistas e natalistas na sociedade brasileira, torna-se necessário recuperar alguns determinantes históricos para a situação hoje prevalente em ter mos do planejamento da reprodução humana.

\section{A REPRODUÇÃO HUMANA}

\section{NO BRASIL - OS DETERMINANTES HISTORICOS}

Embora o interesse pela regulação da fertilidade remonte às sociedades primitivas ${ }^{13}$, o planejamento da reprodução humana, enquan. to movimento, iniciou-se por volta de 1922 nos Estados Unidos, através da militância da enfermeira Margareth Sanger. Surgiu em decorrência das transformações ideológicas radicais pelas quais passava a so-

* Enfermeira. Professora assistente do Departamento de Enfermagem em Saúde Coletiva da Escola de Enfermagem da Universidade de são Paulo. 
ciedade norte-americana da época, advindas principalmente da industrialização e urbanização e que haviam determinado transformações no papel da mulher e da família. No espaço de duas décadas, entretanto, o que começara como movimento contestador em prol dos direitos da mulher e de denúncias ao capitalismo, havia se transformado em movimento conservador de controle social, com destinação específica a certos grupos populacionais. Daí que seus programas no âmbito externo estivessem voltados para as populações da Ásia, Africa e América Latina ${ }^{18}$.

No Brasil, a discussão em torno da regulação dos nascimentos iniciou-se na década de 60 , quando o governo norte-americano de John Kernedy tentou condicionar sua ajuda econômica para a América Latina à adoção de programas que visassem conter o crescimento populacional. ${ }^{8}$. Diferentemente do que acontecera com intervenções semelhantes levadas a cabo em países africanos e asiáticos, tal política não foi bem sucedida em uma América de tradição latina e católica ${ }^{14}$. BARROSO ${ }^{4}$ salienta, inclusive, que "o fato desses programas serem apresentados como uma exigência econômica, os transformava em um preço a ser pago". Também a sua imposição por uma potência estrangeira fez com que tanto a direita quanto a esquerda nacionais se insurgissem contra a ingerência externa nos assuntos internos do país.

Ainda assim, a proposição neo-malthusiana das políticas populacionais emanadas das agências controlistas internacionais, que concebiam o controle da natalidade como uma solução para os problemas econômicos mundiais, encontrou ecos entre a elite conservadora brasileira. Para estas, a ameaça concreta que representava o crescimento das camadas pobres da população, pondo em risco a própria ordem social vigente, representou argumento decisivo para que tais idéias grassassem no seio da classe dominante brasileira ${ }^{14}$.

Não podendo se valer dos argumentos de ordem econômica para justificar sua implantação no Brasil, os programas buscaram assegurar sua efetivação invocando razões biológicas, como a paridade e as gestações de alto risco afetando a saúde das mulheres; razões sociais, como a desproporção entre o número de filhos e os recursos das famílias mais pobres; e razões sanitárias, entre elas o controle do aborto provocado. Foi respaldada nesses argumentos que a classe dominante brasileira assumiu a implementação do controle da natalidade, através de fundações privadas apoiadas pelo governo, com recursos nacionais e internacionais ${ }^{14}$.

Reconstruindo o momento histórico que favoreceu o surgimento dos programas de controle da reprodução no Brasil, verifica-se que os problemas relativos ao desenvolvimento econômico que o país enfrentava já na década de 50, a industrialização incipiente levanđo a um incremento da urbanização, aliados a um crescimento populacional elevado, se comparado com o de países mais desenvolvidos naquela época, se constituiram no pano de fundo que possibilitou a aceitação dos argumentos neo-malthusianos ${ }^{12}$. 
Assim, iniciou-se uma preocupação política com a dinâmica populacional que, chocando-se com as tradições católicas e latinas da sociedade brasileira, manifestou-se de forma ambígua no posicionamento das entidades governamentais de então. Por um lado, o Estado brasileiro difundia um discurso natalista baseado em alegações de soberania nacional, poderio dos exércitos e ocupação dos espaços geográficos vazios do país. Por outro, permitiu a instalação e subsidiou através de isenção de impostos, a instalação de instituições privadas que desenvolviam programas gratuitos de planejamento familiar, graças a dotações financeiras de agências internacionais 7,8,9,19.

O debate que se seguiu à implantação desses programas, sob a conivência do poder estatal, se estendeu por todos os segmentos da sociedade, inclusive entre aqueles que partilhavam esse poder, como é o caso das Forças Armadas Brasileiras. A Igreja Católica, porém, talvez tenha sido o maior opositor a uma política governamental mais explícita em termos de controle da natalidade. Utilizando-se de argumentos mais políticos que de ordem religiosa, atribuindo as soluções dos problemas populacionais a um desenvolvimento econômico-social mais justo e equitativo e não à "desnatalização" dos casais, evitava assim o confronto com suas alas mais progressistas ligadas à Teologia da Libertação ${ }^{6,12}$.

Essa ambigüidade também se evidenciava na postura natalista assumida pelo governo brasileiro em termos de políticas sociais, que concediam os auxílios natalidade e maternidade, além do benefício do salário-família ${ }^{14}$.

\section{AS POLFTICAS SOCIAIS E A REPRODUÇÃO BIOLÓGICA HUMANA}

Uma análise mais acurada das políticas sociais no Brasil, mais especificamente as de saúde, onde se inserem as questões ligadas ao planejamento da reprodução biológica humana, permite verificar que estas políticas são duras conquistas da classe trabalhadora, que as obtém quando se aguçam os conflitos entre as classes sociais. Tratamse de concessões do Estado à classe trabalhadora quando esta, na sua luta por equiidade social, põe em risco a ordem social vigente. São, portanto, transformações sociais que se dão dentro de determinados limites, de forma a não afetar a estrutura que possibilita a existência do modo de produção capitalista ${ }^{1,10,15,17}$.

Ainda assim, comenta, as pressões dos diferentes grupos sociais são importantes agentes fermentadores das mudanças sociais:

\footnotetext{
"Muito embora a adoção de políticas de saúde pública e mudan. ças legislativas dependam, em última instância, de relações de poder, estas não estarão imunes à divulgação de informações que ajudem a dissipar os mitos que sustentam o controle da sexualidade feminina pelo Estado." 3
} 
E desta forma que BARROSO ${ }^{3}$ procura explicar o papel do movimento feminista nas transformações do enfoque que se dava até então à reprodução humana:

\begin{abstract}
"Foi num contexto político polarizado entre natalistas e antina. talistas que o movimento de mulheres - atento às necessidades con. cretas de regulação da fecundidade criadas por transformações da economia e da sociedade latino-americana, com profundas mudanças na familia e na posição da mulher na sociedade - conseguiu intro. duzir novo eixo de discussão centrado no direito individual da mulher decidir soberanamente sobre seu corpo e sua vida."
\end{abstract}

Os atributos que o Estado capitalista confere à mulher, quais sejam, os de reprodutora e socializadora primeira das crianças, se fundamentam na mística da subalternidade feminina a qual justifica que se lhe atribua como principal função a da maternidade ${ }^{16}$. Essa dupla determinação social evidencia o quanto as questões da mulher permeiam aquelas ligadas à reprodução dos corpos, ou reprodução biológica propriamente dita, e à reprodução social.

As mulheres, na sua luta pela auto-determinação reprodutiva, adentram pelo questionamento de seus direitos políticos, sociais e econô. micos. Assim, o acesso aos meios anticoncepcionais, ainda que possa se constituir num reforço à subordinação das mulheres, quando con. trolado pelo Estado, pode também representar uma estratégia de autoproteção para essas mesmas mulheres, em uma sociedade capitalista e patriarcal.

Petchescky, citada por BARROSO ${ }^{3}$, chega a afirmar que:

"Onde as mulheres estão ligadas por fortes laços de trabalho ou de comunidade, onde elas têm acesso a fontes não-domésticas de su. brevivência, onđe a maternidade não é o único trabalho feminino culturalmente valorizado, e onde sistemas alternativos de saúde re. produtiva florecem apoiados por uma comunidade feminina atuante, aí florece uma 'cultura' de controle da fecundidade, incluindo $o$ aborto..."

A associação entre as questões da mulher e as demográficas não é gratuita e as políticas de regulação da natalidade e seu impacto sobre a condição feminina têm sido objeto de várias críticas. A primeira refere-se à pouca qualidade dos serviços de regulação da fecundidade oferecidos à mulher, onde os cuidados médicos são precários ou inexistentes, o acesso aos diferentes métodos é limitado e as necessidades psicológicas da mulher muito pouco atendidas. A segunda diz respeito ao conteúdo ideológico das mensagens que visam difundir a necessidade de se limitar o número de filhos. A terceira volta-se para o fato de que os programas de planejamento da reprodução humana são concebidos e desenvolvidos sem uma articulação mais ampla com o contexto social onde a mulher desenvolve sua prática reprodutiva. 


\section{A REPRODUÇĀO BIOLÓGICA E A REPRODUÇÃO SOCIAL}

A compreensão da reprodução humana como um fenômeno que se expressa coletivamente, uma vez que afeta grupos populacionais, leva ao seu entendimento mais amplo. Assim, não se limita o seu planejamento ao âmbito de ação e decisão dos indivíduos, sejam eles homens ou mulheres, e suas famílias. Enquanto fenômeno social, a reprodução biológica humana também se articula aos processos de reprodução social, próprios das classes sociais e é sobredeterminada pelo desenvolvimento da capacidade produtiva da sociedade e pelas relações sociais de produção.

Portanto, além da reprodução biológica, é preciso considerar que as classes sociais se reproduzem através do trabalho e do consumo, trabalho aqui definido como o conjunto de "atividades realizadas com gasto de energia para a transformação da natureza". As formas de consumo, por sua vez, definem-se como sendo "o conjunto de bens naturais diretos e meios de subsistência socialmente produzidos a que tem direito uma classe social" 5 .

A maneira como o trabalho é realizado vai determinar o padrão de desgaste e repouso do trabalhador e também a intensidade com que ele se expõe a riscos ou benefícios no seu trabalho ou ambiente próximo. O montante que recebe da venda de seu trabalho condiciona a qualidade e quantidade de seu consumo, bem como a necessidade ou não de trabalho familiar complementar. Juntos, trabalho e consumo modelam o perfil reprodutivo social de uma classe, determinados pela estrutura da sociedade concreta onde esta se insere.

Assim, a reprodução biológica dos seres humanos não é a única a determinar a reprodução da força de trabalho de uma determinada classe, pois é necessário considerar também sua reprodução social. No proletariado, sobre esses dois tipos de reprodução atuam as pressões ideológicas a fim de renovar e repetir a sua força de trabalho em função das demandas de cada estágio de desenvolvimento do capitalismo.

OLIVEIRA, M.A. de C. The historical determinations of the human biological reproduction in Brazil. Rev. Esc. Enf. USP, v. 26, n. 2, p. 155-60, Aug. 1992.

The author presents some of the historical determinations of the policies of human reproduction in Brazil, placing them among other social policies. She argues that reproductive profile of the social classes depends upon not only the biological reproduction, but also upon the work power.

UNITERMS: Human biological reproduction. Familiar planning. Natality control.

\section{REFERENCIAS BIBLIOGRAFICAS}

1. AlBUQUerque, J.A.G. Da assistência à disciplina: o programa de saúde comunitária. São Paulo, PROHASA, s.d., p.1-129/mimeografado.

2. BarRoso, C. Esterilização feminina: liberdade e opressão. Rov. Saúde Pábl., v. 18, n. 2, p. 170-80, 1984. 
3. BARROSO, C. A saúde da mulher. São Y’aulo, Nobel, 1985.

4. BARROSO, C. Direitos reprodutivos: a realidade social e o debate político. Cad. Pesq., n. 62, p. 52-9, 1987.

5. BREILH, J.; GRANDA, E. Investigacão da suúde na sociedade: guia pedagógico sobre um novo enfoque do método epidemiológico. São Paulo, Instituto de Saúde, 1986.

6. BRUSCHINI, C.; BARROSO, C. Construindo a política a partir da vida pessoal: discussões sobre a sexualidade entre mulheres pobres no Brasil. São Paulo, Fundação Carlos Chagas, 1984.

7. CANESQUi, A.M. A saúde da mulher em debate. Saúde Deb., n. 15/16, p. 29-36, 1984.

8. CANESQUI, A.M. A implantacão e expansão dos serviços de planejamento familiar: questões e controvérsias. Rev. Paul. Lnf., v. 5, n. 1, p. 26-30, 1985.

9. CENTRO BRASIlEIRO DE ESTUDO DE SAÚDE. (CEBES) Projeto de assistência integral à saúde da mulher: algumas interrogações. Saúde Deb. n. 18, p. 34-7, 1984.

10. GUIMARāes, A.S.A. Estrutura e formação das classes sociajs na Bahia. Novos Eat. CEBRAP, n. 18 , p. 57-69, 1987.

11. OLIVEIRA, F. de. Malthus e Marx: falso encanto e dificuldade radical. Campinas, NEPO/ UNICAMP, 1985.

12. PEREIRA, J.C. Aspectos sociais da contracepção. Ci. e Cult., v. 37, n. 11, p. 1172-8, 1980.

13. PETCHESKY, R. Liberdade reprodutiva: além do direito da mulher escolher. Signs, v. 5, n. 4, p. 1-19, 1980.

14. RODRIGUES, M.J.B. da R. Um estudo sobre o neomalthusianismo no Brasil (1965-1970). São Paulo, 1979. 135 p. Dissertação (Mestrado) - Faculdade de Filosofia, Letras e Ciências Humanas, Universidade de são Paulo.

15. ROSSI, S.A. A constituição do sistema de saúde no Bragil. São Paulo, Departamento de Medicina Social da Faculdade de Ciências Médicas da Santa Casa, 1980. p. 1-43, 70-80.

16. SAFFIOTI, H.I.B. A mulher na sociedade de classes: mito e realidade. Petrópolis, Vozes, 1976.

17. SANTOS, W.G. dos. Cidadania e justica: a politica social na ordem bragileira. Rio de Janeiro, Campus, 1979.

18. SHARPE, J. The birth controllers. In: DREIFUS, C. Seiving our bodies: the politics of women's health. New York, Vintage Books, 1978.

19. SouzA, B.M. de. Saúde: a ambivalência das políticas. Cad. CEBRAP, n. 29, p. 23-44, 1978. 